\title{
The Role of UK Local Authorities in Promoting the Bus
}

\author{
Michelle Morris, Stephen Ison, and Marcus Enoch \\ Loughborough University, Leicestershire, UK
}

\begin{abstract}
To deal with rising city center congestion and its associated pollution, the UK government has proposed a number of policy measures. In particular, the 1998 White Paper indicated that "the bus industry will make an important and cost-effective contribution to tackling congestion and pollution at the local level."

Since the privatization of the bus industry during the 1980s, local government-the primary agents of delivering transport policy objectives in the UK-have had relatively little control over the provision of bus services in their localities, particularly outside London. One area in which local authorities can exert influence, however, is through the promotion of buses among the general public.

So far though, little evidence exists to reveal the extent to which local authorities in the UK have actively promoted city bus services as part of an integrated solution to reducing traffic-related congestion in urban areas. This paper seeks to redress this issue.

The empirical evidence gained in this study suggests that only a few UK local authorities have actively promoted city bus services and that there are problems in establishing cohesive promotional objectives, budget setting, measurement activity, understanding of the promotional mix, and the benefits derived from promoting city bus services.
\end{abstract}




\section{Introduction}

Congestion is a problem not only for the individual motorist, in terms of delay, uncertainty and stress, but also for society as a whole. In particular, congestion has impacts on the environment in terms of higher emissions and pollutants, noise, vibration, and visual intrusion, and it has implications for public health and safety. Bonsall (2000) recognizes that policymakers have become increasingly focused on finding a solution to these escalating levels of urban traffic congestion. This is shown by the UK Department of Environment, Transport and the Regions' White Paper, A New Deal for Transport: Better for Everyone (DETR 1998), which outlined the government's approach in tackling current transport problems; and in Transport 2010: The Ten-Year Plan for Transport (DETR 2000), which set out how it would deliver this over the subsequent decade.

One key element was seen as the increased use of the bus. Indeed, in his foreword to the White Paper, UK Deputy Prime Minister John Prescott stated that congestion and pollution could be combatted by "persuading people to use their cars a little less-and public transport a little more." The White Paper further noted that "the bus industry will make an important and cost-effective contribution to tackling congestion and pollution at the local level" (DETR 1998).

In a survey of local authorities, Ison and Wall (2002) found that 90 percent of the local authorities and academics surveyed believed improved frequency and reliability of public transport is an "effective" policy for dealing with traffic-related congestion, while 95.5 percent deemed improving public transport as the most "acceptable" policy option.

Crucially, local authorities are expected to "play a leading role" in delivering policies to mitigate congestion (DETR 1998). But, while in the capital the London Regional Transport Act (1984) placed most public transport under direct local government control (albeit with private operators), there is rather less scope for intervention elsewhere. This is because, in the rest of the country, the Transport Act (1985) abolished quantity regulation for the local bus industry and privatized bus operations. Enoch (1998) suggested that the role of the local authority was therefore "reduced to providing infrastructure, information and filling in 'gaps' in the commercial network." Preston (2003) added that the deregulated system provides little capacity for government intervention.

Despite this, local authorities do still have a role to play in supporting bus services, and one way of doing this is through marketing and promoting bus services. This 
is a particularly attractive option, not least since it can be seen as cost effective. For instance, the TAS Partnership (1998) found that for every $£ 1.00$ spent on "effective service promotion and branding," the payback was $€ 3.10$. This ranks highly in comparison to the "hard" technology improvements, which produce yields ranging from $£ 1.20$ to $£ 2.20$, per $£ 1.00$ spent.

\section{Table 1. Return Per $£ 1.00$ of Expenditure on Buses}

\begin{tabular}{lc}
\hline \multicolumn{1}{c}{ Measure } & $\begin{array}{c}\text { Approximate } \\
\text { Return per } \\
\text { Pound Spent } \\
(£)\end{array}$ \\
\hline Service simplification & 3.50 \\
Effective service promotion and branding & 3.10 \\
High-quality signage and information & 2.80 \\
Bus stop improvements & 2.20 \\
New buses & 1.80 \\
Bus priority measures such as bus lanes and signal priority & 1.60 \\
Real -time passenger information/automatic vehicle location & 1.20 \\
equipment & \\
\hline
\end{tabular}

Source: TAS Partnership 1998.

Enoch and Potter (2002) indicate that, despite such evidence, examples of promotion and branding in the British bus industry have been "the exception rather than the rule." Preston (2003) confirms this statement by suggesting, "Entrepreneurial scarcity has often been a problem in the bus industry." Furthermore, Barta and Erl (2002) believe that many operators have neglected the "soft" measures (such as promotion) in favor of the "hard" measures (such as new vehicles).

Local authorities are, on the whole, "not-for-profit" organizations. Bean and Hussey (1997) indicate that, within the public sector, large investments in promotion may be seen as a waste of resources that could be spent on direct service delivery. This suggests promotional activities are therefore kept to a minimum. If councils want large numbers of private car users to shift to alternative modes of transport, such as buses however, they have "not only to build capacity in public transport ... they must also market it" (Meiklejohn 2003). 
This article seeks to assess the role of UK local authorities in promoting the bus as an alternative to the private car and the issues this raises.

\section{Promotion}

Dommermuth (1989) indicates that promotion incorporates any technique, under the seller's control, that communicates positive and persuasive information about the product to the potential buyer. In this case, local authorities need to communicate information to both users and nonusers of bus services.

Promotion can play an important role in marketing services. As stated by Jobber (1998), a customer may find difficulty in evaluating a service prior to purchase. The tangible cues used in promotion can therefore help the customer assess the service product. Gubbins (1996) indicates that promotion seeks to convert customer needs into positive patronage of a service.

Hibbs (1989) indicates that there are four "stepping stones" to successful communication with the chosen market, using the mnemonic AIDA: gain Attention, hold Interest, arouse Desire, and obtain Action from the potential customer. This continuous process is reflected in the promotional objectives and the chosen methods of promotion.

The six promotional objectives for a transport company put forward by Majaro (1974:121) are to:

- create awareness of a company's services among potential users;

- generate detailed knowledge of the company' products and services;

- improve the company's image among existing and potential users so as to improve the customers' attitude toward the company;

- eliminate perceived misconceptions;

- advise existing and potential customers of any special offers or modifications to the services; and

- advise the marketplace of new sales channels.

However, Jobber (1998) indicates that objectives set for a private sector company may not be transferable to nonprofit organizations. Bean and Hussey (1997) suggests that the public sector will often be motivated by the desire to: 
- increase public awareness of service provision;

- increase usage;

- demonstrate value for money; and

- educate users.

The marketing strategy (of which promotion is a key part) is the medium to long-term plan for meeting the specified marketing objectives. Within the public transport market, however, it would seem the use of general marketing strategies and plans "is not common" (Barta and Erl 2002).

For a promotional plan to be implemented, there must be supporting resources for the activities to be carried out; that is, a financial/manpower budget. The key question is: How much should the promoter invest? Wilmshurst (1993) suggests, "It is a particularly difficult question to answer." Table 1 shows the effectiveness of spending on bus promotion. The spend/payback ratio could be used to assist in the development of the promotional budget.

Dommermuth (1989), however, indicates that, for firms with large advertising expenditures, the three most widely employed methods of budget calculation are arbitrary allocation, affordability, and percentage of sales. Wilmshurst (1993) recommends "aligning budgets to the competition." Shimp (1993) puts forward the "objective and task method," also noting that this is the most frequently used method by both consumer and industrial companies.

\section{The Promotional Mix}

The promotional mix is concerned with the methods available to communicate with customers. Different authors suggest different methods of promotion; there is no fixed mix. Wilmshurst (1993) advises that "the most appropriate promotional techniques must be chosen to build the best promotional mix." The following list is based on the promotional mix set forth by Dommermuth (1989), Jobber (1998), Hibbs (1989), Lovelock et al. (1999), and Wilmshurst (1993).

- Advertising incorporates any paid form of communication within the prime mass media.

- Personal selling covers the face-to-face, two-way communication between the users/nonusers of the service and the promoter. Wilmshurst (1993) suggests this is more effective than advertising, but more expensive. 
- Sales promotion utilizes incentives to encourage purchase and attempts to promote immediate sales of the product/service. Sales promotion seeks to produce activity and interest at the point of sale.

- The aims of direct marketing are to both acquire new customers and retain existing ones by distributing information and promotional benefits to target consumers through interactive systems of communication. Jobber (1998) suggests it is unlike other communication forms because it usually requires immediate response, facilitating effective measurement of success.

- Like advertising, publicity is directed at a nonpersonal mass audience. In this case, however, the promoter does not directly pay for publicity.

- Good public relations are based upon establishing communications and relationships with a range of stakeholders including employees, shareholders, the media, government, pressure groups, and the local community.

Overall, as stated above, the promotional mix seeks to gain attention, to hold interest, to arouse desire, and to obtain action from potential customers (Hibbs 1989:12).

\section{Research Method}

The Transport Act 2000 in England and Wales and the Transport (Scotland) Act 2001 in Scotland provided local authorities with the power to introduce schemes to charge for use of congested roads or workplace parking. Twenty-five authorities initially expressed an interest in charging and as such became part of the "Charging Development Partnership" (House of Commons Transport Committee 2003). Their interest in congestion charging suggested that they suffer from traffic-related congestion, a situation in which public transport could play an important role.

As such, the survey was sent to the local authorities throughout the UK who formed part of the Charging Development Partnership. Of the surveys sent, 15 were completed and returned. Although this is a small sample, it represents a significant proportion of the urban areas in the UK, providing a clear account of a number of the issues involved in terms of promoting the use of the bus. Named respondents include Bristol City Council, Devon County Council, Durham County Council, Edinburgh City Council, Greater Manchester Passenger Executive, London Buses/Transport for London, Milton Keynes City Council, Nottingham City Council, Reading Borough Council, Southampton City Council, Tyne and Wear Passenger Transport Executive and West Midlands Passenger Transport Executive. 
In addition, three respondents requested anonymity. They are referred to as A1, $A 2$, and $A 3$. An electronic/postal survey was used to gather the data, which was of a semistructured design.

The survey constituted a mixture of closed questions, quick-response tick boxes, open-ended questions, and spaces for comments. The core of the survey centered on which elements of the "promotional mix" the local authority used, and how. Supplementary questions then probed for further supportive material surrounding the promotion of buses within local authorities. The most sensitive and probing questions, such as the promotional budget, were left until the end of the questionnaire.

\section{Survey Findings and Discussion}

From the survey, all but two of the local authorities promote the use of their city bus services. Two local authorities, A2 and Edinburgh City Council, ${ }^{1}$ do not use promotion, while of the remaining 13 , all target nonusers of the service, and all except Southampton City Council, target existing users. Of those who do use promotion, A1 and London Buses/TfL are the only two authorities to use external companies to carry out promotional activities. Three authorities (A3, Nottingham City Council, and Tyne and Wear PTE) use a combination of "in-house" resources and external agencies, and the remaining eight authorities only use "in-house" resources.

\section{Objectives}

When asked about the objectives for promotional activity, all 13 authorities responded positively stating that their objectives were to:

1. reduce traffic congestion by directly reducing car use;

2. support other traffic measures such as road charging;

3. increase ridership/patronage;

4. influence modal shift in favor of public transport (not directly recognizing congestion);

5. support social policy; and

6. promote awareness of the bus services. 
Only Durham and the West Midlands PTE revealed a direct link between their objectives for bus promotion and reducing traffic congestion in their urban areas.

The majority of the local authority activities were linked to awareness, increasing ridership, and influencing modal shift in favor of public transport, with no direct stated link to congestion reduction.

\section{Promotion}

Asked if their promotional activities were part of a wider integrated strategy such as reducing city center congestion, 12 authorities indicated that they were, of which 3 (Devon County Council, London Buses/TfL and Reading Borough Council) showed direct links to a reduction of traffic congestion. Gubbins (1996) suggests that promotion seeks to convert customer needs into positive patronage of a service. But, while 5 of the local authorities specify "increasing ridership/patronage" as one of their promotional objectives, only 2 authorities (A3 and London Buses/TfL) have increased patronage of their city bus services. The remaining 11 authorities are either unsure of growth patterns or have fluctuating, static, or negative growth in bus usage.

Aspects of Hibbs's (1989) stepping stones to successful market communications were also investigated. The results reveal that all 13 local authorities that promote the use of their city bus services are fulfilling the first step to successful market communications, that of gaining attention (A), since all are actively seeking publicity and good public relations. Meanwhile, the final stepping stone suggested by Hibbs is to obtain action (A) - an action that can only really be measured by the level of promotional activity undertaken. From the sample of authorities who promote the use of the city bus services, only 8 assess their success in achieving action as a result of their promotional activity.

The second and third stepping stones, to hold interest (I) and to arouse desire (D), are more difficult to measure. This is because although all promotional methods contained within the promotional mix are designed to catch the public's interest, the survey only provided a "snapshot" of current activities and did not ascertain the views of the general public. This is an area for further research. 


\section{Use of the Promotional Mix}

As noted previously, the "best" promotional mix comprises advertising, personal selling, sales promotion, direct marketing, publicity, and public relations. Each local authority was asked whether they employed each of the promotional techniques. Of the 13 local authorities who indicated that they promote the use of the city bus services, 11 use advertising, 4 use personal selling, 9 practice sales promotion, 7 use direct marketing, and all use publicity and public relations.

\section{Advertising}

Of the 13 local authorities, 11 promote the use of bus services using various methods of advertising. Of these, 10 advertise city bus services in local and regional newspapers, 9 use billboard posters, 8 advertise via the radio, 8 advertise on board the bus, and 6 place promotional ads in magazines and make use of the side of buses. The cinema is used in a minority of cases, as are national newspapers, while none of the sample promote city bus services via TV advertising. Other methods of advertising, which were not part of the promotional framework, included use of bus stop display cases, timetables, local travel guides, free-standing advertising panels, posters on other city public transport, and free newspapers such as the London Metro.

\section{Personal Selling}

Of the 13 local authorities, 4 use personal selling to promote the use of the city bus services. Of these, 2 use shops and retail outlets, rely on employees of the bus service, and recognize customer "word of mouth" as a method of personal selling. None of the authorities make use of their city's bus drivers at point of sale, nor do they promote bus usage through telemarketing sales teams.

\section{Sales Promotion}

Of the 13 local authorities, 9 use methods of sales promotion. Bulk ticket purchasing is the most commonly used ( 6 of the 9 authorities), while 4 offer free trial journeys for nonusers, 3 use prize promotions, 2 provide money off bus use, and 1 provides passengers with loyalty cards.

\section{Direct Marketing}

Of the 13 local authorities who promote the use of city bus services, 7 utilize direct marketing techniques, 9 use their website as a tool for direct marketing activity, 7 perform door-to-door leafleting, and 6 send direct mail and use inserts. Only 2 make use of email, while the same number suggested "other" methods of direct marketing including ticket wallets/cardholders and giveaways such as stress toys. 
None of the respondents use interactive TV, outbound/inbound telemarketing, or direct response as methods of direct marketing to support the promotion of bus usage.

\section{Publicity and Public Relations}

All 13 local authorities use specific methods of publicity to secure good public relations, with the most common method used being press releases. A total of 5 partake in special events, are visible at exhibitions, and provide sponsorship.

\section{Promotional Budget}

A total of 11 of the authorities indicated that they have a budget for the promotional activities supporting the use of their city's buses. Of these, 1 authority could not disclose the details, and another had no set amount for bus promotion within an "all mode" budget. The 9 authorities' budgets, including details of budget spending, are shown in Table 2.

\section{Table 2. Local Authority Budgets and Promotional Spending per Capita}

\begin{tabular}{|c|c|c|c|c|}
\hline Authority & Prior Year (E) & $\begin{array}{c}\text { Current Year } \\
(E)\end{array}$ & $\begin{array}{c}\text { Population } \\
\text { Size }\end{array}$ & $\begin{array}{c}\text { Promotional } \\
\text { Spending per } \\
\text { Head }(E)\end{array}$ \\
\hline \multicolumn{5}{|l|}{ Southampton City } \\
\hline Council & 3,000 & 5,000 & 215,000 & 0.02 \\
\hline Tyne \& Wear PTE & (+) 30,000 & $(+) 30,000$ & $1,075,000$ & 0.03 \\
\hline \multicolumn{5}{|l|}{ Nottingham City } \\
\hline Council & 50,000 & N/A & 750,000 & 0.07 \\
\hline Bristol City Council & 44,570 & 45,460 & 402,300 & 0.11 \\
\hline A3 & 100,000 & 100,000 & 355,000 & 0.28 \\
\hline \multicolumn{5}{|l|}{ Milton Keynes City } \\
\hline Council & Not known & (c.) 90,000 & approx. 200,000 & 0.45 \\
\hline London Buses/TfL & (c.) $5,000,000$ & (c.) $5,000,000$ & $7,000,000$ & 0.71 \\
\hline \multicolumn{5}{|l|}{ Devon County } \\
\hline Council & 130,000 & 130,000 & 110,000 & 1.18 \\
\hline \multicolumn{5}{|l|}{ Durham County } \\
\hline Council & 50,000 & 50,000 & 40,000 & 1.25 \\
\hline
\end{tabular}


A total of 10 authorities commented on the basis for setting the annual bus promotional budgets. Affordability was mentioned by 8 of the respondents, 4 had budgets dependent on objectives/task, and one had a budget based on a percentage of sales. A total of 3 of the respondents used a combination of criteria to set their promotional budgets.

Shimp (1993) indicated that the objective and task method was the most frequently used technique by both consumer and industrial companies, but it would seem that, for UK local authorities, affordability was the most commonly used basis for setting the budget for bus promotion. Interestingly, none of the authorities surveyed supported Wilmshurst (1993), who suggested another method was to match spending to the competition. This is likely due to the fact that the competition in this case would be the car industry, which spends heavily on promotional activities to support the sale of cars.

Barta and Erl (2002) raise the question, Who is responsible for marketing public transport? There would appear to be confusion surrounding ownership responsibilities, with a lack of consistency across the UK.

Within the local authorities, promotion is carried out by a variety of departments ranging from transport planning, transport policy, and transport strategy, to dedicated marketing, promotions, and advertising executives. Making contact with the correct department and responsible persons was difficult due to this inconsistency.

The survey respondent's job titles/roles also varied. The majority were completed by individuals in public/passenger transport departments. This high percentage supports Vigar and Stead (2003), who indicate that local authorities may lack experience and expertise when implementing marketing schemes to increase bus patronage, in this case promoting the use of buses. The research revealed that a minority of the responses were from advertising/promotions or marketing managers.

The variance in scope for local authority promotion within the two regulatory structures of the bus industry was noted earlier. London Buses/TfL verified this by suggesting "one of the big advantages we have in London (as part of the Greater London Assembly) is control over public transport (i.e., we can set service levels and monitor performance)." Perhaps unfortunately, within the UK this is a unique situation, as elsewhere “...under the Transport Act 1985, the council's influence 
is limited to an arm's-length relationship with the (bus) company" (City of Edinburgh Council).

\section{Conclusions and Recommendations}

The research revealed that local authorities in the UK claim to be promoting the use of city buses. There would appear, however, to be a lack of organizational consistency within the authorities surveyed and uncertainty as to who is responsible for bus promotion, whether it be the operator or the authority.

There would also appear to be a dearth of cohesive promotional objectives in support of local authority bus promotion. This lack of clarity leads to unclear strategies and, in turn, unclear choices of promotional mix elements and consequent plans.

Budgets are essential if promotion is to be actively carried out. The research has revealed that further assistance may be required to support the development of local authority promotional budgets. The benefits of investing in bus promotion have, in general, not been realized. Affordability is the main driver and does not reflect an aim/cost-benefit budget.

Only 6 of the 13 respondents measured the effectiveness of promotion before and after activity/spending. Subjective assessments revealed a general lack of confidence in their promotional success.

From this limited, targeted sample, generalizations should be treated with caution. The authors suggest, however, that the findings have validity and that a number of recommendations can be made.

First, in terms of central government, a supportive framework stemming from central government should promote bus use as part of an overall strategy to manage demand for the private car.

Central government policy clearly stresses the need to reduce traffic-related congestion within the UK. Various solutions to this problem are provided, including promoting the use of public transport. For these solutions to be executed at the local level and fully integrated with government policy, authorities need to be provided with methods and guidance on how to design and implement the solutions. 
Second, there is clearly a need for more consistency in terms of the authorities/ departments responsible for promoting the use of city bus services across the UK. However, as the Royal Commission on Environmental Pollution report (1997) noted, "restructuring government departments does not in itself guarantee that coherent policies will emerge."

Third, as for local authorities, it is suggested that they consider the following issues:

- the need to integrate local bus promotion with central government policy;

- the need to identify clear promotional aims and objectives;

- the importance of establishing an appropriate budget/spending; and

- the need for measurement before and after the promotional activity to appraise whether the objectives have been met and aid continuous improvement in the planning processes.

The promotion of buses, not least in supporting the reduction of traffic congestion, is a noncompetitive activity. Local authorities should be aware of the opportunities for best practice information sharing between like-minded professionals for the common benefit of users and potential users of the bus services. It is important to note, however, that following deregulation, it is difficult for local authorities to get too involved in any aspect of service provision. How local authorities can promote the use of the bus without jeopardizing the requirement for public sector neutrality is an area requiring further research.

\section{Acknowledgments}

The authors would like to thank all those interviewed during the course of this research.

\section{Endnote}

${ }^{1}$ The reason for this could be that there are two competing bus companies, making it difficult to preserve neutrality. This has relevance for other localities. 


\section{References}

Barta, F., and E. Erl. 2002. State of the art analysis report, working group 1-Public transport market and customer relations. Voyager Network. Report to DG TREN Clean Transport Unit, European Commission, Brussels, November. Available at http://www.voyager-network.org (last accessed 29/03/05).

Bean, J., and L. Hussey. 1997. Marketing public sector services. HB Publications, London.

Bonsall, P. 2000. Legislating for modal shift: background to the UK's new transport act. Transport Policy 7 (3): 179-184.

Department of Environment, Transport and the Regions. 1998. A new deal for transport: Better for everyone. Department of Environment, Transport and the Regions, The Stationery Office, London.

Department of Environment, Transport and the Regions. 2000. Transport 2010: The ten-year plan for transport. Department of Environment, Transport and the Regions, The Stationery Office, London, July.

Dommermuth, W. 1989. Promotion, analysis, creativity, and strategy, 2nd ed. PWSKent Publishing Company, Boston.

Enoch, M. P. 1998. Bus-based best-practice and urban transport emissions, Ph.D. Thesis, Energy and Environment Research Unit, The Open University, Milton Keynes, February.

Enoch, M. P., and S. Potter. 2002. Marketing and the British bus industry. Municipal Engineering 151 (1): 49-56.

Gubbins, E. J. 1996. Managing transport operations, 2nd ed. Kogan Page, London.

Hibbs, J. 1989. Marketing management in the bus and coach industry. Croner Publications, London.

House of Commons Transport Committee. 2003. First report, Section III-urban charging schemes. The Stationery Office, London.

Ison, S., and Wall, S. 2002. Attitudes to traffic related issues in urban areas of the UK and the role of workplace parking charges. Journal of Transport Geography 10 (1): 21-28.

Jobber, D. 1998. Principles and practice of marketing, 2nd ed. McGraw-Hill, London. 
Lovelock, C., S. Vandermerwe, and B. Lewis. 1999. Services marketing: A European perspective. Financial Times/Prentice Hall, Harlow.

Majaro, S. 1974. Transport needs marketing. Journal of General Management 1(3).

Meiklejohn, D. 2003. Smart travel in demand. EECA, Australia, April/May. Available at: http://www.eeca.govt.nz/content/ew_news/81may03/travelsmart.html (last accessed 11/11/03).

Preston, J. 2003. A Thoroughbred in the Making? The Bus Industry under Labour. In ed. Docherty, I., Shaw, J., A new deal for transport? Blackwell Publishing, Oxford.

Royal Commission on Environmental Pollution. 1997. Twentieth report. Transport and the environment: Developments since 1994. Cmnd 3752, The Stationery Office, London.

Shimp, T. A. 1993. Promotion management \& marketing communications, 3rd ed. The Dryden Press \& Harcourt Brace Jovanovich College Publishers, Orlando.

TAS Partnership. 1998. Modal shift: Essential components of success. Proceedings of a Local Transport Today/TAS Partnership Conference: The Role of Buses in the New Transport Policy Environment, London, 28 June.

Vigar. G., and D. Stead. 2003. Local Transport Planning under Labour (Chapter 3). In ed. Docherty, I., Shaw, J., A new deal for transport? Blackwell Publishing, Oxford.

Wilmshurst, J. 1993. The fundamentals of advertising. Butterworth Heinemann, Wiltshire.

\section{About the Authors}

MICHELLE MORRIS is currently studying for an MSc in human resource management and business at Aston University (UK). Her first degree was in transport management and planning gained from Loughborough University (UK). Ms. Morris has worked in transport planning for WS Atkins in Birmingham (UK). Her research interests include transport services marketing, transport demand management, and the environmental impacts of congestion.

STEPHEN ISON (s.g.ison@lboro.ac.uk) is a lecturer in transport studies at Loughborough University. He obtained an MA in transport economics from ITS, Leeds and 
a PhD in road user charging and implementation from Loughborough University. He has 20 years' experience in transport research, mainly in the area of transport policy and economics. Dr. Ison has published more than 30 articles in the area of transport policy and a number of books, most recently Road User Charging: Issues and Policies (Ashgate 2004) and Environmental Issues and Policies (Financial Times/ Prentice Hall 2002). His work has involved highlighting good practice in terms of implementing car parking charges at the workplace.

MARCUS ENOCH (m.p.enoch@lboro.ac.uk) is a lecturer in transport studies at Loughborough University in the UK, where he has worked since transferring from a postdoctoral research fellowship at the Open University in January 2003. He has particular research interests in several areas including the implementation, financing, and operation of transport demand management measures; the factors affecting the efficiency and effectiveness of buses, demand responsive transport systems, and car clubs; and transport within small island developing states. He has conducted a number of research projects over the last decade for clients including the European Commission, UK government departments, UK local authorities, and UK academic research councils. Dr. Enoch is also a freelance transport news and photo journalist. 